\title{
Treatment Principles for the Management of Mold Infections
}

\author{
Dimitrios P. Kontoyiannis ${ }^{1}$ and Russell E. Lewis ${ }^{2}$ \\ ${ }^{1}$ The University of Texas M.D. Anderson Cancer Center, Houston, Texas 77030 \\ ${ }^{2}$ Department of Medical Sciences and Surgery, University of Bologna, 40138 Bologna, Italy \\ Correspondence: dkontoyi@mdanderson.org
}

Survival rates among immunocompromised patients with invasive mold infections have markedly improved over the last decade with earlier diagnosis and new antifungal treatment options. Yet, increasing antifungal resistance, breakthrough infections with intrinsically resistant fungi, and potentially life-threatening adverse effects and drug interactions are becoming more problematic, especially with prolonged therapy. Evidence-based recommendations for treating invasive aspergillosis and mucormycosis provide excellent guidance on the initial workup and treatment of these molds, but they cannot address all of the key management issues. Herein, we discuss 10 general treatment principles in the management of invasive mold disease in immunocompromised patients and discuss how these principles can be integrated to develop an effective, individualized treatment plan.

In this review, the principles around the treatment and management of infections by both yeasts and molds are discussed. The work herein covers mold infections and treatment issues; for coverage of the principles of treatment around yeast infections with an emphasis on Candida and Cryptococcus infections (Whitney and Bicanic 2015).

These companion works provide a unique format to give important and insightful principles about how we can and should manage invasive mycoses. There are a series of textbooks, society guidelines, and electronic information systems like Up-to-Date, which provide the clinician with specific drug doses and antifungal drug selection. However, herein, the clinicians dial down into relevant issues in which every clinician must face when they approach these deadly invasive mycoses. The discussion provides more context into what it means to successfully treat an invasive mycoses by using both evidence-based data and the authors' own clinical experience.

The insights provided are both "state-ofthe-art" and will be valuable for many years to come. Many of these fungal infections are complications during treatment of severe underlying diseases. This review will help inform clinicians about successfully preventing or treating fungal infections so the underlying diseases can be successfully managed. Fungal infections are frequently part of the medical landscape in seriously ill patients today. They are not rare occurrences, but, in many respects,

Editors: Arturo Casadevall, Aaron P. Mitchell, Judith Berman, Kyung J. Kwon-Chung, John R. Perfect, and Joseph Heitman

Additional Perspectives on Human Fungal Pathogens available at www.perspectivesinmedicine.org

Copyright (C) 2015 Cold Spring Harbor Laboratory Press; all rights reserved; doi: 10.1101/cshperspect.a019737

Cite this article as Cold Spring Harb Perspect Med 2015;5:a019737 
the complexity of the underlying host makes their successful management based on certain general principles that must be adapted to individual patients. This work elegantly frames the principles.

Fungal infections, especially opportunistic mold infections, remain a severe complication of immunosuppression associated with the treatment of hematological malignancy and/ or solid organ or hematopoietic stem cell transplantation. Mold infections are associated with substantial healthcare utilization (Tong et al. 2009; Drgona et al. 2013b), and high crude and attributable mortality rates (Pfaller and Diekema 2010). Invasive fungal infections are also associated with poorer outcomes of underlying diseases, as hematologists or transplant physicians are often less reluctant to proceed with lifesaving immunosuppressive chemotherapy or transplantation in the setting of active fungal disease (Cordonnier et al. 2004; Even et al. 2011). In this article, we review the principles of management of those infections, focusing mostly on aspergillosis, which accounts for the majority of such infections. However, these principles can be similarly applied to other opportunistic non-Aspergillus mold infections such as Mucorales, Fusarium, and Scedosporium infections. We organized treatment into 10 principles for consideration in the individual patient, which are broadly applicable to different institutions and treatment practices. It is important to have a systematic approach to antifungal management, as the number of treatment options for invasive molds have increased and each antifungal has unique advantages and disadvantages for the specific patient and time of use (i.e., prophylaxis, empiric, preemptive, and targeted therapy). Specifically, in 2014, we have five different classes of antifungals indicated for systemic fungal infections, and over 12 approved drugs.

\section{PRINCIPLE 1: KNOW THE SPECTRUM OF ACTIVITY OF COMMONLY USED ANTIFUNGALS}

The three major classes of modern antifungals used in the treatment of mold infections con- sist of: the triazole antifungals (posaconazole, voriconazole), the echinocandins (caspofungin, micafungin, anidulafungin) and AMB-based therapy. All those classes of drugs have their own limitations in terms of coverage for different molds. For example, voriconazole has excellent activity against Aspergillus species (Pfaller et al. 2011) and modest activity against Fusarium species (Espinel-Ingroff 2001). Voriconazole also has good activity against Scedosporium apiospermum (Lewis et al. 2005). However, it lacks an important coverage against the $M u$ corales and Scedosporum prolificans (Espinel-Ingroff 2001). Unlike voriconazole, posaconazole is active Mucorales, although some isolates have intrinsically high MICs (minimum inhibitory concentration) that may be untreatable with the current oral formulation (Spreghini et al. 2010). A new triazole currently under development with both intravenous (IV) and oral formulations, isavuconazole, also displays good activity against Aspergillus spp. with some coverage of Mucorales (Falci and Pasquallotto 2013).

The echinocandins inhibit growth of Aspergillus species, even though this class lacks true fungicidal activity in vitro and in vivo (Bowman et al. 2002). Hence, many clinicians use echinocandins as monotherapy for invasive aspergillosis only in situations of less severe disease, after immune reconstitution, as a second-line agent when other drugs cannot be tolerated, or in combination with a second antifungal (Herbrecht et al. 2010). Echinocandins have limited activity against non-Aspergillus molds, such as the Mucorales, Fusarium, and Scedosporium spp., although some animal infection models have suggested they can be effective if administered in combination with a triazole or lipid AMB formulation. Finally, AMB-based regimens have a broad spectrum of activity with the exception of some uncommon molds, such as Scedosporium, Fusarium species. Thus, the prescribing physician, who treats patients with a variety of mold infections, would benefit from knowing the full spectrum of activity of drugs, especially in the context of preemptive and targeted treatment of invasive mold infections. 
PRINCIPLE 2: KNOWLEDGE OF THE PATHOGENESIS AND NATURAL HISTORY OF MOLD INFECTIONS IS ESSENTIAL FOR EFFECTIVE USE OF ANTIFUNGAL THERAPY IN HIGH-RISK PATIENTS

Most antifungals are prescribed for prophylaxis or empirical treatment based on clinical signs and symptoms such as persistent fever. Preemptive and targeted treatment courses of antifungals generally account for no more than 30\% of those treatment episodes (Freemantle et al. 2011; Norkin and Wingard 2013). Consequently, many patients are needlessly exposed to antifungal agents to prevent or empirically treat a few infections that will only occur in a minority $(6 \%-15 \%)$ of the at-risk population (de Pauw 2005). This indiscriminate antifungal use reflects our incomplete understanding of the pathogenesis of invasive mold disease, as well as difficulties associated with early and accurate diagnosis (de Pauw and Viscoli 2011). Nevertheless, continued refinement of risk models based on clinical factors and/or genomic profiles may improve our ability to identify the subset of pa- tients who are most likely to benefit from antifungal prophylaxis with broad-spectrum agents.

In the United States, and many other countries, empiric therapy remains the predominant approach for antifungal use, especially in the setting of persistent neutropenic fever (Fig. 1). In other parts of the world, particularly European countries, there is increasing reliance on serum biomarkers and/or computerized tomography (CT) as the "triggers" for preemptive antifungal treatment (Drgona et al. 2013a). However, the sensitivity of these diagnostic markers and imaging techniques can vary from one population to the next, and at different stages of the underlying malignancy treatment or transplant (Maertens et al. 2011). It is sometimes impossible to "rule out" an early invasive mold infection based solely on these biomarkers and/or CT imaging, and, hence, empirical antifungal therapy remains a judicious treatment approach until immune status improves or more diagnostic information becomes available.

Finally, clinicians must recognize that cultures and histopathology are rarely positive until relatively late in the course of an invasive mold

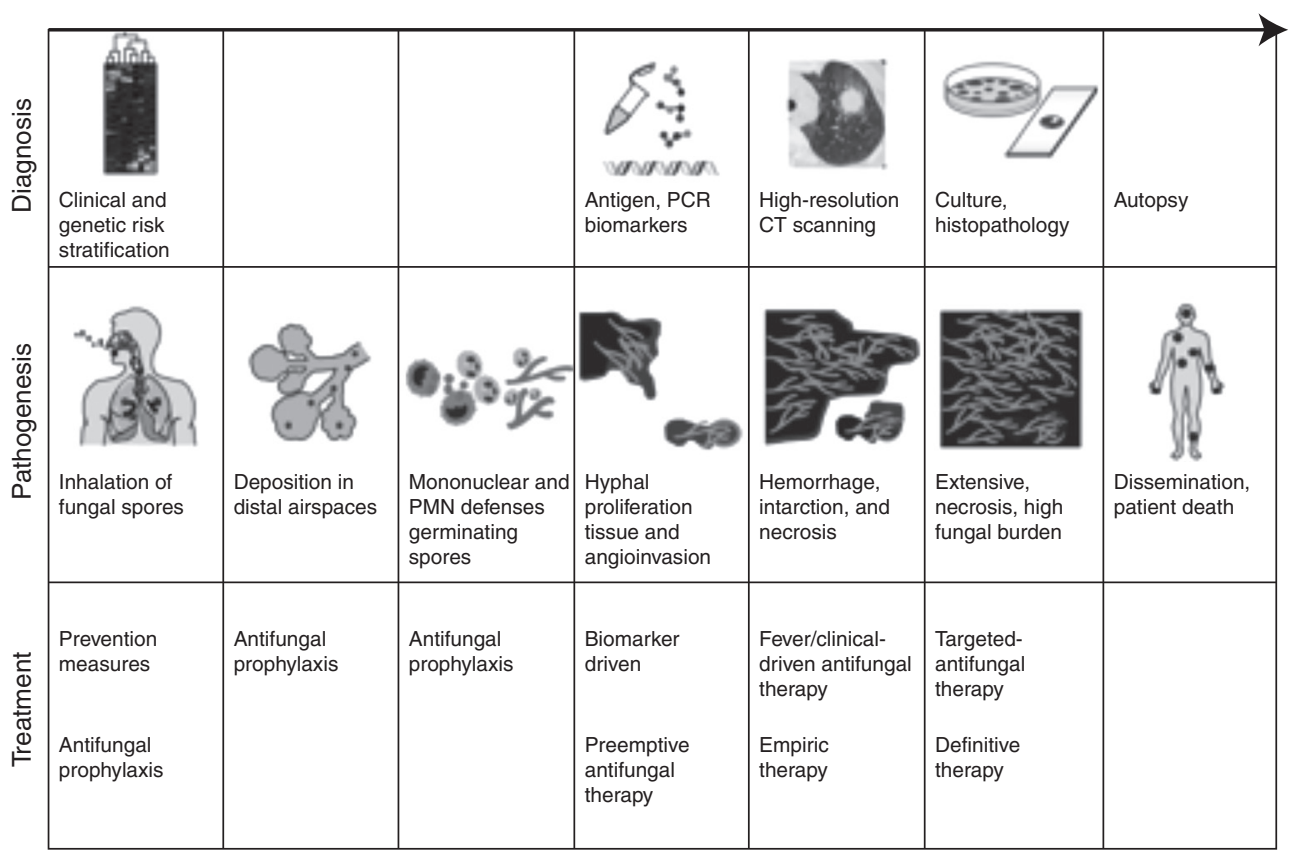

Figure 1. The continuum of invasive mold infection. PCR, polymerase chain reaction; CT, computerized tomography. 
infection (Fig. 1), when the fungal burden is high (Baddley et al. 2010; Hope et al. 2010; Chai et al. 2012). Even so, culture and histopathology data are often essential for targeting current therapy and future secondary prophylaxis approaches, especially with respect to orally administered agents against specific fungi. The major need in the field is to identify the optimal treatment period, when undetected fungal proliferation occurs, as antifungals started at this point are most likely to abrogate full expression of severe opportunistic fungal infection.

\section{PRINCIPLE 3: IT IS IMPORTANT FOR THE CLINICIAN TO KNOW THE PHARMACOKINETIC AND PHARMACODYNAMIC BEHAVIOR OF ANTIFUNGALS}

Even the most broad-spectrum antifungals have notable pharmacokinetic limitations. These limitations are driven by the fact that these agents when given orally may not be absorbed in the setting of mucositis or poor appetite, as is the case with posaconazole (Dolton et al. 2012). Serum levels may also be highly unpredictable because of host genetic variability in cytochrome P450 metabolism, as is the case with voriconazole (Lee et al. 2012), or because of pharmacokinetic drug-drug interactions, which are numerous with all triazole antifungals (Brüggemann et al. 2009). In addition, several antifungals have limitations in penetration of some sites of infection, such as the brain and eye (e.g., the echinocandins, posaconazole, itraconazole) (Gauthier et al. 2005) or the urine (e.g., the echinocandins, voriconazole, posaconazole) (Cornely et al. 2012). Therefore, "staging" of the infection for potential or likely sites of dissemination is essential for choosing an appropriate antifungal that will target critical sites of infection.

Knowledge of concomitant medications and potential pharmacokinetic and toxicodynamic interactions of antifungal agents with other drugs used in the transplant or oncology setting is essential (Brüggemann et al. 2009). Importantly, any clinician prescribing antifungals should review the patient's medication record for possible drug-drug interactions and the increased risk of drug toxicities (i.e., renal toxicity, hepatotoxicity, neurotoxicity, etc.). Communications with the primary team caring for the patient, especially in the transplant or hematological malignancy patient, are essential before initiating, changing, or stopping antifungal therapy that alters or inhibits the metabolism and clearance of chemotherapy or immunosuppression regimens-especially for voriconazole and posaconazole (Table 1) (Brüggemann et al. 2009). Antifungal drug interactions with immunosuppressive agents such as cyclosporine and tacrolimus, in particular, predispose the patient not only to increase short-term adverse effects such as kidney, liver, and neurological toxicities, but also to increase longer-term risk for malignancy relapse, organ rejection, or graft versus host disease if adequate immunosuppression is not provided in the early period posttransplant. Renal dysfunction associated with AMB can be especially problematic in the allogeneic transplant patients, because any increased toxicity leading to severe renal injury will interfere not only with immunosuppression protocols (i.e., calcineurin inhibitors), but also the administration of other essential therapies that may be required to control bacterial (vancomycin, aminoglycosides, colistin) or viral infections (i.e., acyclovir, foscarnet) (Saliba and Dupont 2008).

Pharmacokinetic interactions that increase clearance of antifungals through enzyme induction, such as coadministration of voriconazole or posaconazole with rifampin, phenytoin, or other inducers of cytochrome P450 3A4 (CYP3A4), are similarly dangerous because they may result in inadequate antifungal drug exposures and breakthrough infections in such patients (Brüggemann et al. 2009). Gastric pH plays an important role in the dissolution and absorption of posaconazole in the gastrointestinal tract (Dodds-Ashley 2010). Coadministration of posaconazole suspension during acid suppression therapy with $\mathrm{H} 2$ blockers but even more so proton-pump inhibitors, often results in undetectable plasma levels in patients who already have poor appetite, nausea, or diarrhea (Kohl et al. 2009; Dolton et al. 2012; 
Table 1. Critical drug interactions with voriconazole and posaconazole

\begin{tabular}{|c|c|c|}
\hline Drug group & $\begin{array}{l}\text { Effect elicited on concomitant drug by } \\
\text { triazole }\end{array}$ & Management \\
\hline $\begin{array}{l}\text { Antineoplastic drugs } \\
\text { (cyclophosphamide, } \\
\text { busulfan, vincristine, } \\
\text { tyrosine kinase inhibitors) }\end{array}$ & $\begin{array}{l}\text { Altered metabolism of clearance of } \\
\text { antineoplastic agents leading to } \\
\text { increased toxicity }\end{array}$ & $\begin{array}{l}\text { Avoid concomitant use, initiate } \\
\text { triazole antifungal } 1 \mathrm{~d} \text { after } \\
\text { completion of chemotherapy }\end{array}$ \\
\hline $\begin{array}{l}\text { Immunosuppressants } \\
\text { (cyclosporine, tacrolimus, } \\
\text { sirolimus, corticosteroids) }\end{array}$ & $\begin{array}{l}\text { Increased levels of } \\
\text { immunosuppressant (inhibition of } \\
\text { clearance), increased risk or central } \\
\text { nervous system adverse effects }\end{array}$ & $\begin{array}{l}\text { Monitoring of calcineurin inhibitor } \\
\text { concentrations, dose adjustments } \\
\text { required when initiating or } \\
\text { stopping triazole }\end{array}$ \\
\hline $\begin{array}{l}\text { QT-prolonging medications } \\
\text { (e.g., antiarrythmics, } \\
\text { fluoroquinolones, } \\
\text { macrolides, antipsychotics) }\end{array}$ & $\begin{array}{l}\text { Triazoles have been associated with } \\
\text { dangerous QTc prolongation and } \\
\text { development of torsades des pointes }\end{array}$ & $\begin{array}{l}\text { Careful assessment of risk versus } \\
\text { benefit, especially in patients with } \\
\text { prolonged QTc, electrolyte } \\
\text { abnormalities }\end{array}$ \\
\hline $\begin{array}{l}\text { Benzodiazepines (midazolam, } \\
\text { other hypnotics) }\end{array}$ & $\begin{array}{l}\text { Increased effect caused by decreased } \\
\text { clearance }\end{array}$ & Dose adjustment \\
\hline Warfarin & $\begin{array}{l}\text { Significant increases in prothrombin } \\
\text { time }\end{array}$ & $\begin{array}{l}\text { Dose adjustment of warfarin with } \\
\text { close monitoring }\end{array}$ \\
\hline $\begin{array}{l}\text { Statins (simvastatin, } \\
\text { atorvastatin) }\end{array}$ & $\begin{array}{l}\text { Decreased clearance, increased risk of } \\
\text { muscle toxicity (rhabdomyolisis) }\end{array}$ & $\begin{array}{l}\text { Close monitoring with possible dose } \\
\text { reduction or discontinuation of } \\
\text { statin }\end{array}$ \\
\hline Rifampin & $\begin{array}{l}\text { Increased triazole clearance, increased } \\
\text { risk of therapeutic failure }\end{array}$ & Avoid concomitant use \\
\hline Phenytoin, carbamazepine & $\begin{array}{l}\text { Increase triazole clearance, increased } \\
\text { risk of therapeutic failure }\end{array}$ & $\begin{array}{l}\text { Avoid concomitant use if possible, } \\
\text { adjust triazole dose by therapeutic } \\
\text { drug monitoring }\end{array}$ \\
\hline
\end{tabular}

Cojutti et al. 2013). A new intravenous and tablet formulation of posaconazole that circumvent the need for acidic gastric $\mathrm{pH}$ is expected soon and will likely improve many of these treatment-limiting pharmacokinetic issues of posaconazole suspension (Krishna et al. 2012).

Finally, the pharmacokinetic behavior and optimal dosing strategy for echinocandins and triazoles in pediatrics (Lehrnbecher et al. 2011), the morbidly obese (Pai and Bearden 2007; Pai and Lodise 2011), or critically ill septic patients (Hoenigl et al. 2013) are still being defined. Even in the absence of these conditions, the considerable pharmacokinetic variability of voriconazole and posaconazole makes it almost impossible to predict the likely range of drug exposure (plasma levels), even when doses are administered on a $\mathrm{mg} / \mathrm{kg}$ basis (Andes et al. 2008).

Therefore, use of voriconazole and posaconazole in pediatric patients, as well as any other patient with suspected impaired absorption, unexplained toxicity, breakthrough infection, or recent switch to oral therapy, should be considered for therapeutic drug monitoring (TDM) (Andes et al. 2008). Provisional guidelines are available for monitoring both voriconazole, and posaconazole. The target blood concentrations may depend on the indication. For voriconazole prophylaxis, a target trough concentrations of $0.5 \mu \mathrm{g} / \mathrm{mL}$ has been proposed, with levels between 1.5 and $5 \mathrm{mg} / \mathrm{L}$ recommended for therapy of a presumed or documented infection (Pascual et al. 2012). Several studies have documented that the risk of neurological adverse effects during voriconazole therapy increases exponentially at trough concentrations $>5 \mathrm{mg} / \mathrm{L}$ (Pascual et al. 2008, 2012). For posaconazole, a target serum trough concentration of $0.5-0.7 \mathrm{mg} / \mathrm{L}$ has been suggested for prophylaxis (Dolton et al. 2012; Vaes et al. 2012), with trough concentrations 
of $0.5-1.5 \mathrm{mg} / \mathrm{L}$ preferred in patients with suspected or documented infection. Trough concentrations $>1.5 \mathrm{mg} / \mathrm{L}$ may be preferable in patients receiving posaconazole for mold infections with higher MICs to the drug such as Mucorales, if possible.

\section{PRINCIPLE 4: KNOW THE ADVERSE EFFECTS OF ANTIFUNGALS}

Antifungal medications target fungi that are eukaryotic organisms. Not surprisingly, these drugs have some toxicities in humans that can be magnified or accelerated in medically complex patients receiving multiple medications. Immunologic reactions during drug infusions are more problematic with $\mathrm{AMB}$, owing to the drug's direct stimulatory effect on mononuclear cells, which results in fever, chills, and rigors (Rogers et al. 1998). Histamine-like reactions can also occur with the liposomal AMB formulations, but are less common than the histamine reactions seen in echinocandin infusions because of their lipopeptide structure (analogous to the Red-Person syndrome observed with vancomycin) (Eschenauer and DePestel 2007). Gastrointestinal intolerance has been an issue with itraconazole and posaconazole solutions, which are often unpalatable in patients who already have nausea associated with other medications or chemotherapy (Cornely et al. 2007; Nagappan and Deresinski 2007; Ullmann et al. 2007).

The major dose-limiting adverse effects during antifungal therapy are renal toxicity, which is manifested by acute tubular necrosis and impaired glomerular filtration with AMB formulations, and hepatic toxicity, which can occur with all antifungal medications. Renal toxicity is a well-known side effect of AMBbased regimens that can be reduced or delayed by avoiding other nephrotoxins, ensuring adequate hydration of the patient, and by administering lipid or liposomal formulation (Saliba and Dupont 2008). Intravenous formulations of itraconazole, voriconazole, and posaconazole (in development) are solubilized in cyclodextran vehicles, which carry a theoretical risk of reversible kidney injury reflected in the product labeling, but has not been an issue in over a decade of clinical use in patients with renal dysfunction and/or dialysis (Álvarez-Lerma et al. 2008; Hafner et al. 2010).

Antifungal associated hepatotoxicity has been reported most frequently with itraconazole, voriconazole, and, to a lesser extent, lipid AMB formulations or echinocandins (Wang et al. 2010). Generally, hepatotoxicity manifests as a progressively rising hepatocellular (increasing serum transaminases), cholestatic (increasing alkaline phosphatase, total bilirubin), or as mixed hepatocellular-cholestatic markers with variable range of onset and drug exposure (Song and Deresinski 2005). Idiosyncratic (immunemediated) reactions are rare, but have been associated with acute liver failure with antifungals (Song and Deresinski 2005). Because of its nonspecific manifestations, management of suspected antifungal hepatotoxicity is an empirical process frequently confounded by multiple underlying causes (i.e., other medications, graft vs. host disease of the liver, concomitant viral infections, malignancy, or fungal infiltration of the liver) (Chamilos et al. 2007). Although serum transaminases occasionally normalize without drug or dosage modification, it is more common to temporarily withhold antifungal medications, switch to another class of antifungals, or a different agent within the same class (i.e., switch to posaconazole from voriconazole) and observe whether liver function improves (Spellberg et al. 2003).

Central nervous system (CNS) side effects, especially hallucinations or visual changes (photopsia), are problematic and sometimes treatment limiting adverse effects of voriconazole. More commonly, CNS side effects are reversible with drug discontinuation and TDM-guided dosage reduction, as their manifestations are frequently related to elevated voriconazole plasma trough concentrations (Pascual et al. 2008).

Improved supportive care and survival following transplantation and treatment of hematological malignancies has also increased the number of patients who receive antifungal therapy for prolonged periods (months to years). A 
number of longer-term toxicities may manifest over time especially with triazoles, including cardiovascular dysfunction (especially itraconazole) (Fung et al. 2008), phototoxic reactions, increased risk of squamous cell carcinoma (voriconazole) (Clancy and Nguyen 2011), fluoride excess, periostitis with voriconazole (Wermers et al. 2011), and peripheral neuropathies (Baxter et al. 2011). Therefore, proactive screening for these long-term toxicities and continuous reassessment of the risk versus benefit of continuing therapy is essential among patients who remain on antifungal therapy for prolonged periods.

\section{PRINCIPLE 5: EARLY DIAGNOSIS IS THE MOST IMPORTANT VARIABLE IN TREATMENT RESPONSE}

Antifungal drugs work well when the inoculum is lowest and the risk of dissemination to other organs is low (Fig. 1). Improved survival attributed to newer antifungals often occurred in the background of increasingly earlier diagnosis and treatment, through high-resolution CT scanning and antigen biomarkers such as the galactomannan test (Freemantle et al. 2011). In the global aspergillosis trial that compared voriconazole versus $\mathrm{AMB}$-deoxycholate plus other therapies (Herbrecht et al. 2002), voriconazole treatment in an early stage of the infection, when there was only one pulmonary nodule and/or halo sign, was associated with an eventual cure rate of $63 \%$ that dropped to $41 \%$ when voriconazole was introduced in the absence of a halo sign or multiple pulmonary nodules (Greene et al. 2007). These results were recently confirmed in the voriconazole plus anidulafungin versus voriconazole monotherapy trial for invasive aspergillosis, in which the benefits of using the combination regimen were observed primarily in patients with galactomannan-antigen diagnosed disease primarily at lower antigen (fungal burden) levels (Marr et al. 2005).

More sensitive biomarkers that allow for earlier diagnosis should translate to better strategies for the use of antifungals. Therefore, there is a consensus in the mycology field that in the future, we shall see an increased reliance and introduction of new, even better biomarkers that would allow us to move away from empiric antifungal therapy (even if we are not quite there yet) and start treatment preemptively for a mold infection.

\section{PRINCIPLE 6: KNOW YOUR LOCAL EPIDEMIOLOGY}

Analysis of the local epidemiology of invasive fungal infections is essential for effective infection control programs and antifungal stewardship. This knowledge is developed through quality improvement processes in the clinical microbiology laboratory that uses traditional and culture-independent diagnostic methods and with an attempt to increase autopsy rates. As an example, at the University of Texas M.D. Anderson Cancer Center in Houston, at least $25 \%$ of mold infections are attributable to Mucorales (Kontoyiannis and Lewis 2011). The relative frequency of invasive mucormycosis increased in the early 2000s after the introduction and routine use of voriconazole in the hematology and transplant populations but even the number of cases had been steadily increasing since the mid-1990s (Kontoyiannis et al. 2005).

Knowledge of the local epidemiology plays a key role for guiding empiric treatment approaches. For example, if early pulmonary mucormycosis is treated as invasive pulmonary aspergillosis with voriconazole-based regimen, the in-hospital mortality doubles, unless AMBbased therapy is introduced in the first 6 days from the onset of the symptoms (Chamilos et al. 2008). Another example is in The Netherlands, where widespread environmental use of azole antifungals has created conditions for a high prevalence voriconazole-resistant Aspergillus fumigatus (owing to the TR/L98H mutation in cyp51A gene that encodes $14 \alpha$-demethylase) (Denning and Bowyer 2013). Voriconazole treatment without consideration that patients may be infected with a voriconazole-resistant isolate has resulted in inappropriate therapy associated with very high $(80 \%)$ mortality rates (Verweij et al. 2007). 
D.P. Kontoyiannis and R.E. Lewis

\section{PRINCIPLE 7: THE PROGNOSIS OF INFECTION IS HEAVILY DEPENDENT ON THE DEGREE AND COURSE OF IMMUNOSUPPRESSION IN THE PATIENT}

Immunosuppression, like immunity itself, is highly individualized and sometimes difficult to define objectively. Nevertheless, clinicians must have a concept of the patient's "net state of immunosuppression" and understanding of future immunosuppression risks when developing an individualized treatment plan. The most common variables in the hematology/oncology patients include: (1) the duration and sequence of immunosuppressive therapy; (2) depth and duration of neutropenia; (3) the number of episodes of neutropenia; (4) the presence of mucositis; and (5) whether the patient has ongoing metabolic issues (e.g., diabetes, or iron overload) or severe catabolic state (malnutrition, hyperglycemia), which is frequently encountered in the late stages of relapsed malignancy (Leventakos et al. 2010). Coinfections, particularly active cytomegalovirus (CMV) replication or other herpesviruses, are important "signposts" of severe immunosuppression (Herbrecht et al. 2012). Old age, refractory leukemia, or refractory graft versus host disease requiring high doses of corticosteroids or anti-T-cell antibodies (i.e., antithymocyte globulin, aletuzumab), lack of neutrophil recovery, polymicrobial infection, poor performance status, and multiple comorbidities are the key indicators of a poor prognosis (Pagano et al. 2010; Herbrecht et al. 2012). Patients with multiple risk factors, who have also received multiple courses of antifungals, are particularly susceptible to infections with resistant fungi, delayed diagnosis, severe pneumonia with rapid dissemination, and death.

Although recovery of host immunity is essential for control of invasive molds, it can sometimes be associated with a series of localized and systemic proinflammatory responses, termed immune reconstitution syndrome (IRS) (Sing and Perfect 2007). IRS most frequently manifests with worsening radiographs or respiratory difficulty when neutrophil counts recover, often with negative cultures or stable/declin- ing antigen biomarkers (galactomannan). The management of IRS remains largely empirical but a course of corticosteroids tapered over at least $3 \mathrm{wk}$ (similar to that recommended for severe Pneumocystis jirovecii pneumonia) may be considered in situations in which the inflammatory reaction is associated with severe organ dysfunction, other life threatening conditions, or CNS manifestations (Sing and Perfect 2007).

\section{PRINCIPLE 8: VARIABLES INFLUENCING THE SELECTION OF AN ANTIFUNGAL AGENT CHANGE IN THE ACUTE VERSUS CHRONIC STATES OF TREATMENT}

For an acutely ill patient, selection of an antifungal should initially focus on agents with the broadest spectrum of activity and pharmacokinetic predictability over patient convenience and risks of future toxicity. In this situation, intravenously administered lipid formulations of $\mathrm{AMB}$, voriconazole, and the echinocandins are generally the preferred agents. For the chronic phase of the disease in which treatment is often completed in the outpatient settings and compliance and tolerability are bigger issues, the convenience of oral triazoles such as posaconazole or possibly voriconazole are preferable, provided the patient can take oral medications. Drug costs may in some cases be a deciding factor of which antifungal prophylaxis is feasible. Likewise, compliance needs to be stressed when taking oral voriconazole and posaconazole, because inconsistency in taking medications will increase not only the risk for breakthrough fungal infection but also creates problems for adjusting and monitoring concomitant immunosuppressive therapies.

\section{PRINCIPLE 9: THE MANAGEMENT OF OPPORTUNISTIC MOLD INFECTION NEEDS MULTIDISCIPLINARY APPROACH}

A coordinated approach by an expert clinical mycologist, in close collaboration with a hematologist, is of paramount importance (Ben-Ami et al. 2013). An experienced microbiologist, pathologist, and pharmacist also play important 
roles in the management of these complex patients. For pulmonary mycoses, an early attempt for a diagnosis with a bronchoscopy, CT-guided aspiration of peripheral lesions requires dedicated pulmonologists and interventional radiologists as members of the multidisciplinary team. In selected cases, dedicated thoracic surgeons could aid with debulking of pulmonary lesions before subsequent transplantation or high intensity chemotherapy. Finally, it is important to highlight the contributions of the nurses and other caregivers, as invasive mold infections are chronic and prone to relapse, requiring frequent contacts with the healthcare system and significant quality of life issues.

\section{PRINCIPLE 10: EVIDENCE-BASED} TREATMENT GUIDELINES ARE A STARTING POINT, NOT A ROADMAP, FOR MANAGING PATIENTS WITH INVASIVE FUNGAL INFECTIONS

Consensus treatment guidelines have been published that provide evidence-based recommendations for the diagnosis and treatment of invasive aspergillosis (Walsh et al. 2008) and empiric treatment of invasive fungal infections in the setting of febrile neutropenia (Freifeld et al. 2011). European guidelines for the management of mucormycosis have been recently developed (Skiada et al. 2012), but are still lacking for other molds such as Fusarium or Scedoporium spp. The treatment recommendations are based, whenever possible, on data from prospective, multicenter randomized trials and graded according to the strength of evidence. Nevertheless, $>30 \%$ of patients who are screened for randomized clinical trials of invasive aspergillosis do not meet criteria for study inclusion because of inadequate (at the time) diagnostic information, comorbidities, or expected poor outcome of the underlying malignancy (Herbrecht et al. 2012). Prior antifungal therapy is also a major confounding variable that influences not only the epidemiology of the infection but also the sensitivity of antigen tests used in diagnosis (i.e., galactomannan, $\beta$ glucan), which have become the decisive factor for enrollment $>80 \%$ of patients included in contemporary clinical trials (Marr et al. 2012).

The challenge of applying clinical trials results to "real-life" practice is clearly illustrated in the recent global comparative trial of voriconazole monotherapy versus voriconazole plus anidulafungin (Marr et al. 2012). This study, which was performed at 93 sites in 24 countries, examined 6-wk all-cause mortality rates in hematological malignancy patients with proven or probable aspergillosis randomized to receive $2-4$ wk of intravenous voriconazole alone, or in combination with an echinocandin that could then be switched to oral voriconazole to complete a 6-wk treatment course. The study excluded patients who were considered to be high risk for early death from malignancy relapse or organ dysfunction. Importantly, enrolled patients had very low rates $(8 \%)$ of prior antifungal prophylaxis, which has become much more common as a standard of care since the introduction of posaconazole. Compared with patients randomized to monotherapy arm, combination therapy was associated with an $8.2 \%$ reduction in all-cause mortality $(P=$ $0.09)$ that increased to $11.6 \%(P<0.05)$ among patients with infection diagnosed by serum or bronchial alveolar lavage galactomannan. Does this mean that the incremental improvement associated with combination therapy applies only to patients who do not receive prophylaxis and have early antigen-based diagnosis? How can this trial be translated into an antifungal stewardship program, given that the increased costs of combination therapy and the fact that the more expensive regimen was beneficial in the lower inoculum (as defined by galactomannan index) patient?

After patients survive their initial episode of mold infection and continue with chronic immunosuppressive therapy, there is a need for continuation of antifungals as secondary prophylaxis (Sipsas and Kontoyiannis 2006). Limited clinical experiences are available to define the optimal strategy for secondary prophylaxis. However, available evidence suggests that secondary antifungal prophylaxis with a triazole, such as voriconazole, can reduce the risk of fungal relapse (Cordonnier et al. 2010). However, 
issues with long-term toxicities of antifungals required further investigation. Other strategies, such as adoptive immunotherapy, granulocyte colony-stimulating factor (G-CSF) - elicited donor white cell transfusions in periods of very high immunosuppression, "bridging" from an oral triazole to an IV-based therapy during pancytopenia, and preemptive surgery before further immunosuppression, are all logical actions and can be applied in individual patients (Sipsas and Kontoyiannis 2006).

\section{SUMMARY}

Clearly, we have come a long way in treating invasive mold infections. However, continued progress is needed in our understanding of the natural history and epidemiology of invasive mold infections, particularly with respect to increasing triazole resistance. Improvements in risk stratification and the development and validation of novel biomarkers will be essential before empirical therapy can finally be abandoned. This will also require rethinking clinical trials design, and consideration of innovative study approaches such as adaptive trials or pharmacometric end points (Rex et al. 2013). Large cooperative data registries are also needed to address key treatment issues that frequently encountered in patients but rarely considered in drug registration trials. Ultimately, restoration of host immunity to fungi is the only path that leads to cure, and remains the most elusive but promising strategy for further reducing patient morbidity and mortality from invasive mold infections.

\section{REFERENCES}

${ }^{*}$ Reference is also in this collection.

Álvarez-Lerma F, Allepuz-Palau A, Gracia MP, Ágeles León M, Navarro A, Sáchez-Ruí H, Iruretagoyena JR, LuqueGóez P. 2008. Impact of intravenous administration of voriconazole in critically ill patients with impaired renal function. J Chemother 1: 93-100.

Andes D, Pascual A, Marchetti O. 2008. Antifungal therapeutic drug monitoring: Established and emerging indications. Antimicrob Agents Chemother 53: 24-34.

Baddley JW, Andes DR, Marr KA, Kontoyiannis DP, Alexander BD, Kauffman CA, Oster RA, Anaissie EJ, Walsh TJ,
Schuster MG, et al. 2010. Factors associated with mortality in transplant patients with invasive aspergillosis. Clin Infect Dis 50: 1559-1567.

Baxter CG, Marshall A, Roberts M, Felto T, Denning DW. 2011. Peripheral neuropathy in patients on long-term triazole therapy. J Antimicrob Chemother 66: 2136-2139.

Ben-Ami R, Halaburda K, Klyasova G, Metan G, Torosian T, Akova M. 2013. A multidisciplinary team approach to the management of patients with suspected or diagnosed invasive fungal disease. J Antimicrob Chemother 68: iii25-iii33.

Bowman JC, Hicks PS, Kurtz MB, Rosen H, Schmatz DM, Liberator PA, Douglas CM. 2002. The antifungal echinocandin caspofungin acetate kills growing cells of Aspergillus fumigatus in vitro. Antimicrob Agents Chemother 46: 3001-3012.

Brüggemann RJM, Alffenaar JWC, Blijlevens NMA, Billaud EM, Kosterink JGW, Verweij PE, Burger DM. 2009. Clinical relevance of the pharmacokinetic interactions of azole antifungal drugs with other coadministered agents. Clin Infect Dis 48: 1441-1458.

Chai LYA, Kullberg BJ, Johnson EM, Teerenstra S, Khin LW, Vonk AG, Maertens J, Lortholary O, Donnelly PJ Schlamm HT, et al. 2012. Early serum galactomannan trend as a predictor of outcome of invasive aspergillosis. J Clin Microbiol 50: 2330-2336.

Chamilos G, Luna M, Lewis RE, Chemaly R, RaadII, Kontoyiannis DP. 2007. Effects of liposomal amphotericin B versus an amphotericin B lipid complex on liver histopathology in patients with hematologic malignancies and invasive fungal infections: A retrospective, nonrandomized autopsy study. Clin Ther 29: 1980-1986.

Chamilos G, Lewis RE, Kontoyiannis DP. 2008. Delaying amphotericin B-based frontline therapy significantly increases mortality among patients with hematologic malignancy who have zygomycosis. Clin Infect Dis 47: $503-$ 509.

Clancy CJ, Nguyen MH. 2011. Long-term voriconazole and skin cancer: Is there cause for concern? Curr Infect Dis Rep 13: $536-543$.

Cojutti P, Candoni A, Simeone E, Franceschi L, Fanin R, Pea F. 2013. Antifungal prophylaxis with posaconazole in patients with acute myeloid leukemia: Dose intensification coupled with avoidance of proton pump inhibitors is beneficial in shortening time to effective concentrations. Antimicrob Agents Chemother 57: 6081-6084.

Cordonnier C, Maury S, Pautas C, Bastiè JN, Cheheta S, Castaigne S, Kuentz M, Bretagne S, Ribaud P. 2004. Secondary antifungal prophylaxis with voriconazole to adhere to scheduled treatment in leukemic patients and stem cell transplant recipients. Bone Marrow Transpl 33: 943-948.

Cordonnier C, Rovira M, Maertens J, Olavarria E, Faucher C, Bilger K, Pigneux A, Cornely OA, Ullmann AJ, Bofarull RM, et al. 2010. Voriconazole for secondary prophylaxis of invasive fungal infections in allogeneic stem cell transplant recipients: Results of the VOSIFI study. Haematologica 95: 1762-1768.

Cornely OA, Maertens J, Winston DJ, Perfect J, Ullmann AJ, Walsh TJ, Helfgott D, Holowiecki J, Stockelberg D, Goh Y-T, et al. 2007. Posaconazole vs. fluconazole or itraco- 
nazole prophylaxis in patients with neutropenia. $N$ Engl J Med 356: 348-359.

Cornely OA, Bassetti M, Calandra T, Garbino J, Kullberg BJ, Lortholary O, Meersseman W, Akova M, Arendrup MC, Arikan-Akdagli S, et al. 2012. ESCMID guideline for the diagnosis and management of Candida diseases 2012: Non-neutropenic adult patients. Clin Microbiol Infect 18: $19-37$.

Denning DW, Bowyer P. 2013. Voriconazole resistance in Aspergillus fumigatus: Should we be concerned? Clin Infect Dis 57: 521-523.

de Pauw BE. 2005. Between over- and undertreatment of invasive fungal disease. Clin Infect Dis 41: 1251-1253.

de Pauw E, Viscoli C. 2011. Managing invasive fungal infections: Relying on clinical instincts or on a rational navigation system? J Antimicrob Chemother 66: S1:i55-i58.

Dodds-Ashley E. 2010. Management of drug and food interactions with azole antifungal agents in transplant recipients. Pharmacotherapy 30: 842-854.

Dolton MJ, Ray JE, Marriott D, McLachlan AJ. 2012. Posaconazole exposure-response relationship: Evaluating the utility of therapeutic drug monitoring. Antimicrob Agents Chemother 56: 2806-2813.

Drgona L, Colita A, Klimko N, Rahav G, Ozcan MA, Donnelly JP. 2013a. Triggers for driving treatment of at-risk patients with invasive fungal disease. J Antimicrob Chemother 68: iii17-iii24.

Drgona L, Khachatryan A, Stephens J, Charbonneau C, Kantecki M, Haider S, Barnes R. 2013b. Clinical and economic burden of invasive fungal diseases in Europe: Focus on pre-emptive and empirical treatment of Aspergillus and Candida species. Eur J Clin Microbiol Infect Dis $1-15$.

Eschenauer G, DePestel DD. 2007. Comparison of echinocandin antifungals. Ther Clin Risk Manag 3: 71-97.

Espinel-Ingroff A. 2001. In vitro fungicidal activities of voriconazole, itraconazole, and amphotericin B against opportunistic moniliaceous and dematiaceous fungi. J Clin Microbiol 39: 954-958.

Even C, Bastuji-Garin S, Hicheri Y, Tulkins P, Botterel F, Maury S, Cabanne L, Bretagne S, Cordonnier C. 2011 Impact of invasive fungal disease on the chemotherapy schedule and event-free survival in acute leukemia patients who survived fungal disease: A case-control study. Haematologica 96: 337-341.

Falci DR, Pasqualotto AC. 2013. Profile of isavuconazole and its potential in the treatment of severe invasive fungal infections. Infect Drug Resist 6: 163-174.

Freemantle N, Tharmanathan P, Herbrecht R. 2011. Systematic review and mixed treatment comparison of randomized evidence for empirical, pre-emptive and directed treatment strategies for invasive mould disease. J Antimicrob Chemother 66: i25-i35.

Freifeld AG, Bow EJ, Sepkowitz KA, Boeckh MJ, Ito JI, Mullen CA, RaadII, Rolston KV, Young J-AH, Wingard JR, et al. 2011. Clinical practice guideline for the use of antimicrobial agents in neutropenic patients with cancer: 2010 update by the Infectious Diseases Society of America. Clin Infect Dis 52: e56-e93.
Fung S-L, Chau C-H, Yew W-W. 2008. Cardiovascular adverse effects during itraconazole therapy. Eur Respir J 32: 240.

Gauthier GM, Nork TM, Prince R, Andes D. 2005. Subtherapeutic ocular penetration of caspofungin and associated treatment failure in Candida albicans endophthalmitis. Clin Infect Dis 41: e27-e28.

Greene RE, Schlamm HT, Oestmann J-W, Stark P, Durand C, Lortholary O, Wingard JR, Herbrecht R, Ribaud P, Patterson TF, et al. 2007. Imaging findings in acute invasive pulmonary aspergillosis: Clinical significance of the halo sign. Clin Infect Dis 44: 373-379.

Hafner V, Czock D, Burhenne J, Riedel KD, Bommer J, Mikus G, Machleidt C, Weinreich T, Haefeli WE. 2010. Pharmacokinetics of sulfobutylether- $\beta$-cyclodextrin and voriconazole in patients with end-stage renal failure during treatment with two hemodialysis systems and hemodiafiltration. Antimicrob Agents Chemother 54: 2596-2602.

Herbrecht R, Denning DW, Patterson TF, Bennett JE, Greene RE, Oestmann J-W, Kern WV, Marr KA, Ribaud P, Lortholary O, et al. 2002. Voriconazole versus amphotericin B for primary therapy of invasive aspergillosis. N Engl J Med 347: 408-415.

Herbrecht R, Maertens J, Baila L, Aoun M, Heinz W, Martino R, Schwartz S, Ullmann AJ, Meert L, Paesmans M, et al. 2010. Caspofungin first-line therapy for invasive aspergillosis in allogeneic hematopoietic stem cell transplant patients: A European organisation for research and treatment of cancer study. Bone Marrow Transplant 45: 1227-1233.

Herbrecht R, Bories P, Moulin J-C, Ledoux M-P, LetscherBru V. 2012. Risk stratification for invasive aspergillosis in immunocompromised patients. Ann NY Acad Sci 1272: 23-30.

Hoenigl M, Duettmann W, Raggam RB, Seeber K, Troppan K, Fruhwald S, Prueller F, Wagner J, Valentin T, ZollnerSchwetz I, et al. 2013. Potential factors for inadequate voriconazole plasma concentrations in intensive care unit patients and patients with hematological malignancies. Antimicrob Agents Chemother 57: 3262-3267.

Hope WW, Petraitis V, Petraitiene R, Aghamolla T, Bacher J, Walsh TJ. 2010. The initial 96 hours of invasive pulmonary aspergillosis: Histopathology, comparative kinetics of galactomannan and $(1 \rightarrow 3)-\beta$-D-glucan, and consequences of delayed antifungal therapy. Antimicrob Agents Chemother 54: 4879-4886.

Kohl V, Muller C, Cornely OA, Abduljalil K, Fuhr U, Vehreschild JJ, Scheid C, Hallek M, Ruping MJGT. 2009. Factors influencing pharmacokinetics of prophylactic posaconazole in patients undergoing allogeneic stem cell transplantation. Antimicrob Agents Chemother 54: 207-212.

Kontoyiannis DP, Lewis RE. 2011. How I treat mucormycosis. Blood 118: 1216-1224.

Kontoyiannis DP, Lionakis MS, Lewis RE, Chamilos G, Healy M, Perego C, Safdar A, Kantarjian H, Champlin R Walsh TJ, et al. 2005. Zygomycosis in a tertiary-care cancer center in the era of Aspergillus-active antifungal therapy: A case-control observational study of 27 recent cases. J Infect Dis 191: 1350-1360.

Krishna G, Ma L, Martinho M, Preston RA, O’Mara E. 2012. A new solid oral tablet formulation of posaconazole: A randomized clinical trial to investigate rising single- and 
D.P. Kontoyiannis and R.E. Lewis

multiple-dose pharmacokinetics and safety in healthy volunteers. J Antimicrob Chemother 67: 2725-2730.

Lee SH, Kim BH, Nam WS, Yoon SH. 2012. Effect of CYP2C19 polymorphism on the pharmacokinetics of voriconazole after single and multiple doses in healthy volunteers. J Clin Pharmacol 52: 195-203.

Lehrnbecher T, Bochennek K, Schrey D, Groll AH. 2011. Antifungal therapy in pediatric patients. Curr Fungal Infect Rep 5: 103-110.

Leventakos K, Lewis RE, Kontoyiannis DP. 2010. Fungal infections in leukemia patients: How do we prevent and treat them? Clin Infect Dis 50: 405-415.

Lewis RE, Wiederhold NP, Klepser ME. 2005. In vitro pharmacodynamics of amphotericin B, itraconazole, and voriconazole against Aspergillus, Fusarium, and Scedosporium spp. Antimicrob Agents Chemother 49: 945-951.

Maertens J, Groll AH, Cordonnier C, la Cámara de R, Roilides E, Marchetti O. 2011. Treatment and timing in invasive mould disease. J Antimicrob Chemother 66: S1:i37-i43.

Marr KA, Laverdiere M, Gugel A, Leisenring W. 2005. Antifungal therapy decreases sensitivity of the Aspergillus galactomannan enzyme immunoassay. Clin Infect Dis 40: $1762-1769$.

Marr KA, Schlamm H, Rottinghaus ST, Jagannatha S, Bow EJ, Wingard JR, Pappas P, Herbrecht R, Walsh TJ, Maertens J, et al. 2012. A randomized, double-blind study of combination antifungal therapy with voriconazole and anidulafungin versus voriconazole monotherapy for primary treatment of invasive aspergillosis. 22nd European Congress of Clinical Microbiology and Infectious Diseases (ECCMID), Abstract LB-2812. London, March 31-April 3.

Nagappan V, Deresinski S. 2007. Posaconazole: A broadspectrum triazole antifungal agent. Clin Infect Dis 45: 1610-1617.

Norkin M, Wingard JR. 2013. Diagnostic strategies for invasive fungal infections in patients with hematologic malignancies and hematopoietic stem cell transplant recipients. J Nat Compr Cancer Netw 11: 941-949.

Pagano L, Akova M, Dimopoulos G, Herbrecht R, Drgona L, Blijlevens N. 2010. Risk assessment and prognostic factors for mould-related diseases in immunocompromised patients. J Antimicrob Chemother 66: 5-i14.

Pai MP, Bearden DT. 2007. Antimicrobial dosing considerations in obese adult patients. Pharmacotherapy 27: 1081-1091.

Pai MP, Lodise TP. 2011. Steady-state plasma pharmacokinetics of oral voriconazole in obese adults. Antimicrob Agents Chemother 55: 2601-2605.

Pascual A, Calandra T, Bolay S, Buclin T, Bille J, Marchetti O. 2008. Voriconazole therapeutic drug monitoring in patients with invasive mycoses improves efficacy and safety outcomes. Clin Infect Dis 46: 201-211.

Pascual A, Csajka C, Buclin T, Bolay S, Bille J, Calandra T, Marchetti O. 2012. Challenging recommended oral and intravenous voriconazole doses for improved efficacy and safety: Population pharmacokinetics-based analysis of adult patients with invasive fungal infections. Clin Infect Dis 55: 381-390.
Pfaller MA, Diekema DJ. 2010. Epidemiology of invasive mycoses in North America. Crit Rev Microbiol 36: 1-53.

Pfaller M, Boyken L, Hollis R, Kroeger J, Messer S, Tendolkar S, Diekema D. 2011. Use of epidemiological cutoff values to examine 9-year trends in susceptibility of Aspergillus species to the triazoles. J Clin Microbiol 49: 586-590.

Rex JH, Eisenstein BI, Alder J, Goldberger M, Meyer R, Dane A, Friedland I, Knirsch C, Sanhai WR, Tomayko J, et al. 2013. A comprehensive regulatory framework to address the unmet need for new antibacterial treatments. Lancet Infect Dis 13: 269-275.

Rogers PD, Jenkins JK, Chapman SW, Ndebele K, Chapman BA, Cleary JD. 1998. Amphotericin B activation of human genes encoding for cytokines. J Infect Dis 178: 1726 1733.

Saliba F, Dupont B. 2008. Renal impairment and amphotericin B formulations in patients with invasive fungal infections. Med Mycol 46: 97-112.

Sing N, Perfect JR. 2007. Immune reconstitution syndrome associated with opportunistic mycoses. Lancet Infect Dis 7: 395-401.

Sipsas NV, Kontoyiannis DP. 2006. Clinical issues regarding relapsing aspergillosis and the efficacy of secondary antifungal prophylaxis in patients. Clin Infect Dis 42: 158491.

Skiada A, Lanternier F, Groll AH, Pagano L, Zimmerli S, Herbrecht R, Lortholary O, Petrikkos GL. 2012. Diagnosis and treatment of mucormycosis in patients with haematological malignancies: Guidelines from the 3rd European Conference on Infections in Leukemia (ECIL 3). Haematologica 98: 492-504.

Song JC, Deresinski S. 2005. Hepatotoxicity of antifungal agents. Curr Opin Invest Drugs 6: 170-177.

Spellberg B, Rieg G, Bayer A, Edwards JE Jr. 2003. Lack of cross-hepatotoxicity between fluconazole and voriconazole. Clin Infect Dis 36: 1091-1093.

Spreghini E, Orlando F, Giannini D, Barchiesi F. 2010. In vitro and in vivo activities of posaconazole against zygomycetes with various degrees of susceptibility. J Antimicrob Chemother 65: 2158-2163.

Tong KB, Lau CJ, Murtagh K, Layton AJ. 2009. The economic impact of aspergillosis: Analysis of hospital expenditures across patient subgroups. Intern J Infect Dis 13: $24-$ 36.

Ullmann AJ, Lipton JH, Vesole DH, Chandrasekar P, Langston A, Tarantolo SR, Greinix H, Morais de Azevedo W, Reddy V, Boparai N, et al. 2007. Posaconazole or fluconazole for prophylaxis in severe graft-versus-host disease. N Engl J Med 356: 335-347.

Vaes M, Hites M, Cotton F, Bourguignon AM, Csergo M, Rasson C, Ameye L, Bron D, Jacobs F, Aoun M. 2012. Therapeutic drug monitoring of posaconazole in patients with acute myeloid leukemia or Myelodysplastic syndrome. Antimicrob Agents Chemother 56: 6298-6303.

Verweij PE, Mellado E, Melchers WJG. 2007. Multiple-triazole-resistant aspergillosis. N Engl J Med 356: 14811483.

Walsh TJ, Anaissie EJ, Denning DW, Herbrecht R, Kontoyiannis DP, Marr KA, Morrison VA, Segal BH, Steinbach WJ, Stevens DA, et al. 2008. Treatment of aspergil- 
losis: Clinical practice guidelines of the Infectious Diseases Society of America. Clin Infect Dis 46: 327-360.

Wang JL, Chang CH, Young-Xu Y, Chan KA. 2010. Systematic review and meta-analysis of the tolerability and hepatotoxicity of antifungals in empirical and definitive therapy for invasive fungal infection. Antimicrob Agents Chemother 54: 2409-2419.
Wermers RA, Cooper K, Razonable RR, Deziel PJ, Whitford GM, Kremers WK, Moyer TP. 2011. Fluoride excess and periostitis in transplant patients receiving long-term voriconazole therapy. Clin Infect Dis 52: 604-611.

* Whitney LC, Bicanic T. 2015. Treatment principles for Candida and Cryptococcus. Cold Spring Harb Perspect Med doi: $10.1101 /$ cshperspect.a024158. 


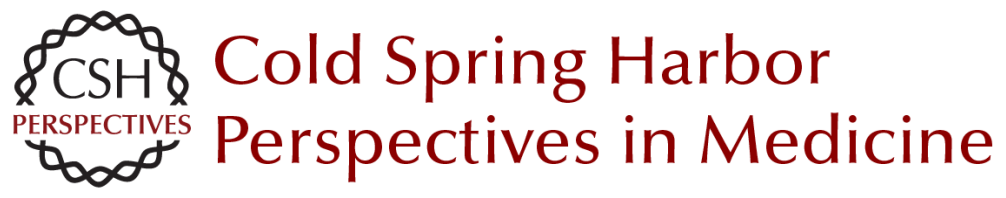

\section{Treatment Principles for the Management of Mold Infections}

Dimitrios P. Kontoyiannis and Russell E. Lewis

Cold Spring Harb Perspect Med 2015; doi: 10.1101/cshperspect.a019737 originally published online November 6, 2014

\section{Subject Collection Human Fungal Pathogens}

\section{Evolutionary Perspectives on Human Fungal Pathogens John W. Taylor}

Black Molds and Melanized Yeasts Pathogenic to Humans Anuradha Chowdhary, John Perfect and G. Sybren de Hoog

Fungal Pathogens: Survival and Replication within Macrophages Andrew S. Gilbert, Robert T. Wheeler and Robin C. May

Innate Defense against Fungal Pathogens Rebecca A. Drummond, Sarah L. Gaffen, Amy G. Hise, et al.

Antifungal Pharmacokinetics and Pharmacodynamics Alexander J. Lepak and David R. Andes

Human Fungal Pathogens of Mucorales and Entomophthorales Leonel Mendoza, Raquel Vilela, Kerstin Voelz, et al.

Functional Profiling of Human Fungal Pathogen Genomes

Alexi I. Goranov and Hiten D. Madhani

Aspergillus fumigatus and Related Species Janyce A. Sugui, Kyung J. Kwon-Chung, Praveen R. Juvvadi, et al.
Thermally Dimorphic Human Fungal Pathogens-Polyphyletic Pathogens with a Convergent

Pathogenicity Trait Anita Sil and Alex Andrianopoulos

Mechanisms of Antifungal Drug Resistance Leah E. Cowen, Dominique Sanglard, Susan J. Howard, et al.

Treatment Principles for Candida and Cryptococcus Laura C. Whitney and Tihana Bicanic

The Human Mycobiome Patrick C. Seed

Treatment Principles for the Management of Mold Infections

Dimitrios P. Kontoyiannis and Russell E. Lewis

Adaptive Immunity to Fungi Akash Verma, Marcel Wüthrich, George Deepe, et al.

The Candida Pathogenic Species Complex Siobhán A. Turner and Geraldine Butler

Fungal Morphogenesis Xiaorong Lin, J. Andrew Alspaugh, Haoping Liu, et al.

For additional articles in this collection, see http://perspectivesinmedicine.cshlp.org/cgi/collection/ 